\title{
Inovação e a capacidade de apropriar benefícios associados aos investimentos em P\&D no Brasil
}

\author{
Raphael Braga da Silva* \\ Luiz Felipe Jacques da Motta** \\ Marcelo Cabús Klötzle*** \\ Antonio Carlos Figueiredo Pinto ${ }^{* * * *}$ \\ Paulo Vitor Jordão da Gama Silva****
}

\section{RESUMO}

Este trabalho busca analisar a capacidade das empresas brasileiras de se apropriarem de benefícios associados aos investimentos em P\&D, seguindo a metodologia proposta por Cohen, Dietther e Malloy (2013), a fim de refletir a capacidade das firmas em converter tais investimentos em vendas (habilidade em vendas). Durante o período de 07/2009 a 07/2014 foi analiso um total de 48 empresas. Além da habilidade em vendas, este trabalho propõe uma nova medida que incorpora os benefícios das inovaçóes em custos (habilidade em margem). Os resultados indicam que, de fato, o mercado de capitais parece ignorar a habilidade de as empresas alocarem seus orçamentos de $P \& D$ com eficiência e sugerem que as inovações

* Pontifícia Universidade Católica do Rio de Janeiro (PUC-Rio), Rio de Janeiro (RJ), Brasil. E-mail: raphael.braga@prof.iag. puc-rio.br.

** Pontifícia Universidade Católica do Rio de Janeiro (PUC-Rio), Rio de Janeiro (RJ), Brasil. E-mail: lfelipe@iag.puc-rio.br.

*** Pontifícia Universidade Católica do Rio de Janeiro (PUC-Rio), Rio de Janeiro (RJ), Brasil. E-mail: klotzle@iag.puc-rio.br.

**** Pontifícia Universidade Católica do Rio de Janeiro (PUC-Rio), Rio de Janeiro (RJ), Brasil. E-mail: figueiredo@iag.puc-rio.br.

***** Pontifícia Universidade Católica do Rio de Janeiro (PUC-Rio), Rio de Janeiro (RJ), Brasil. E-mail: rjdagama@hotmail.com. 
Raphael Braga da Silva, Luiz Felipe Jacques da Motta, Marcelo Cabús Klötzle, Antonio Carlos Figueiredo Pinto, Paulo Vitor Jordão da Gama Silva

associadas ao incremento das vendas produzem retornos futuros maiores do que aqueles associados à redução de custos.

PALAVRAS-CHAVE | Inovação; Investimentos em P\&D; Habilidade em Vendas; Habilidade em Margem

CÓdigo-JEL | O32

\section{Innovation and capacity to appropriate benefits associated with R\&D investments in Brazil}

\section{ABSTRACT}

This paper seeks to analyze the ability of Brazilian companies to appropriate the benefits associated with R\&D investments, following the methodology proposed by Cohen, Dietther and Malloy (2013), in order to reflect the capacity of firms to convert these investments into sales (Ability in Sales). During the period from 07/2009 to 07/2014 a total of 48 companies were analyzed. In addition to Ability in Sales, this paper proposes a new measure that incorporates the benefits of cost innovations (Ability in Margin). The results indicate that in fact, the capital market seems to ignore the ability of firms to efficiently allocate their R\&D budgets, they suggest that innovations associated with sales increase produce future returns greater than those associated with cost reduction.

KEYwORDS | Innovation; Investments in R\&D; Ability in Sales; Ability in Margin

JEL CODE | O32 


\section{Introdução}

O investimento em inovação é um direcionador fundamental de crescimento de longo prazo, dado o seu poder de promover mudanças tecnológicas significativas e alterações nos padrões de produtividade. Dentre as principais métricas da Pesquisa e Desenvolvimento (P\&D) utilizadas para avaliar o impacto do investimento em inovação no valor ou desempenho das firmas, destacam-se:

- os inputs de P\&D como o investimento total em P\&D (LEV; SOUGIANNIS, 1996; CHAN; LAKONISHOK; SOUGIANNIS, 2001; NGUYEN; NIVOIX; NOMA, 2010; SILVA et al., 2015) ou crescimento do investimento em P\&D (PENMAN; ZHANG, 2002; EBERHART; MAXWELL; SIDDIQUE, 2004; LEV; SARATH; SOUGIANNIS, 2005);

- outputs de P\&D, medidos pela quantidade de patentes ou citações de patentes (GU, 2005; PANDIT. WASLEY. ZACH, 2011);

- medidas de eficiência na alocação dos recursos destinados às atividades de $\mathrm{P} \& \mathrm{D}$, mensuradas a partir da relação entre inputs e outputs de P\&D, como quantidade de patentes sobre o investimento em P\&D (HIRSHLEIFER; HSU; LI, 2013) e medidas estatísticas para avaliação da eficiência do investimento em P\&D (COHEN; DIETHER; MALLOY, 2013).

Este trabalho tem como objetivo avaliar se, a despeito da natureza incerta dos dispêndios em P\&D, o histórico da firma na alocação dos seus recursos de P\&D fornecem indícios sobre o seu desempenho futuro e se o mercado de capitais precifica adequadamente empresas mais "hábeis". Para tanto, foi analisado o período de 07/2001 a 07/2014, compreendendo um total de 48 empresas e 2.880 observações em 60 meses.

O estudo baseia-se na metodologia proposta por Cohen, Dietther e Malloy (2013). Os autores estimam uma medida de eficiência que classificam como "habilidade para inovar", baseados na ideia de que determinadas empresas são mais hábeis em certas atividades e tal habilidade é persistente ao longo do tempo. O coeficiente de habilidade proposto pelos autores é previsível e facilmente computável a partir da observação do sucesso passado de uma firma em converter seus investimentos em $P \& D$ em vendas.

Para comparar o desempenho das firmas, utilizou-se uma estratégia de formação de portfólios. A fim de expurgar o efeito das empresas com baixo nível de investimento em P\&D nos resultados, foram formados portfólios de empresas com alta e baixa habilidade para inovar para as aquelas que apresentaram alto P\&D. Além disso, 
realizaram-se análises dos retornos anormais ajustados ao risco por meio dos modelos de três fatores de Fama e French (1993) e de quatro fatores de Carhart (1997). Por fim, foram elaboradas regressões cross-sectional mensais de Fama-MacBeth (1973)

É importante observar que Cohen, Dietther e Malloy (2013) denominam sua métrica de eficiência de "habilidade para inovar", mas o que esta medida captura, de fato, é a eficiência no uso do P\&D. Todavia, ainda que a atividade de inovação organizacional seja fundamentalmente mais ampla do que o investimento em P\&D, abordando ações como a aquisição de bens ou conhecimentos externos, não foram identificadas informações disponíveis capazes de servir como proxy para tais atividades inovativas adicionais ao P\&D. Assim, deve-se deixar claro que sempre que se usar a expressão "habilidade para inovar" neste trabalho, está se fazendo referência à eficiência no uso dos dispêndios em P\&D.

A importância da natureza exploratória deste estudo se justifica pelo crescente interesse do tema para empresas brasileiras inovadoras na área de $\mathrm{P} \& \mathrm{D}$, pelo aumento de investimentos na referida área ao longo dos anos e também pela inexistência de pesquisas semelhantes no Brasil. Também não foram identificados estudos desta natureza em outros países da América Latina. Assim, apesar do curto período de tempo avaliado e da limitação de observaçôes sobre investimento em P\&D no Brasil, esta pesquisa fornece indícios iniciais de uma relação ainda inexplorada no mercado de capitais brasileiro (relações semelhantes já foram investigadas, mas não aquelas específicas entre as variáveis vendas e P\&D).

A seguir é apresentada uma revisão da literatura que trata da relação entre métricas de inovação e o desempenho futuro das firmas. Posteriormente abordam-se a metodologia para estimação dos coeficientes de habilidade, a composição da amostra e o sumário estatístico. Por fim, são discutidos os resultados e tecidas as principais conclusões.

\section{Revisão da literatura}

A literatura internacional não é conclusiva sobre a relação entre o investimento em P\&D e o valor ou desempenho futuro das firmas. Sougiannis (1994) avaliou no mercado norte-americano de 1974 até 1992 a relação entre o investimento em P\&D e o valor de mercado da firma, concluindo que cada dólar investido em P\&D produz um aumento do valor de mercado da ordem de cinco dólares. Todavia, segundo o autor, o efeito direto do P\&D é significativo apenas em seis anos dos 11 avaliados, sendo sua média negativa e não significativa. 
Chan, Lakonishok e Sougiannis (2001) não encontraram evidências que suportem uma relação direta entre investimento em $\mathrm{P} \& \mathrm{D}$ e retornos futuros no mercado estadunidense no período de 1975 a 1995. Enquanto empresas com elevada intensidade medida por P\&D/vendas apresentaram retorno médio de 19,65\% a.a. nos três anos subsequentes ao período de formação do portfólio, aquelas não engajadas em P\&D obtiveram retorno de $19,5 \%$ ao ano. No entanto, para P\&D/ market equity, os autores encontraram evidências de que firmas intensivas em P\&D estão associadas a maiores retornos futuros.

Eberhart, Maxwell e Siddique (2004) estudaram a reação do mercado ao aumento significativo e inesperado do investimento P\&D em 8.313 firmas no mercado norte-americano, entre 1951 e 2001 . Ainda que os autores não tenham utilizado como variável explicativa o investimento total em $\mathrm{P} \& \mathrm{D}$, sua métrica não distingue as empresas com diferentes habilidades para alocarem seus orçamentos de P\&D. Todavia, ainda assim, os autores observaram retornos anormais positivos e significativos nos cinco anos subsequentes ao crescimento inesperado do investimento em P\&D.

Ao compararem o desempenho de empresas líderes e seguidoras, sendo as primeiras as que possuem maior intensidade de $P \& D$ em relação à indústria, Lev, Radhakrishnan e Ciftci (2006) identificaram em seu estudo no mercado estadunidense, para o período de 1975 a 1997, que as empresas líderes sustentam melhor desempenho por pelos menos quatro anos subsequentes, apesar de apresentarem pior rentabilidade no ano corrente. Todavia, assim como Eberhart, Maxwell e Siddique (2004), os autores também concluem que o mercado reage lentamente às informações sobre o benefício do investimento em P\&D, o que pode ser observado em empresas líderes.

Hungarato e Sanches (2006) realizaram um estudo de eventos em empresas listadas na bolsa brasileira, entre 1995 e 2004, e identificaram uma variação positiva e significativa nos retornos anormais das empresas de alta tecnologia, após analisar a variação de preços entre 30 e 60 dias após a divulgação dos gastos com P\&D.

No Japão, durante o período de 1998 a 2007, Nguyen, Nivoix e Noma (2010) não encontraram evidências de má precificação do investimento em P\&D. Usando tanto $\mathrm{P} \& \mathrm{D} /$ vendas quanto $\mathrm{P} \& \mathrm{D} /$ market equity, os autores concluem que no mercado japonês os investidores precificam adequadamente os benefícios do dispêndio em P\&D.

Alves et al. (2010), por sua vez, avaliaram a relação entre gastos em P\&D e o preço das ações no Brasil, entre 2002 e 2009, para as empresas distribuidoras de energia elétrica, dado que as empresas deste setor são obrigadas a aplicar um percen- 
Raphael Braga da Silva, Luiz Felipe Jacques da Motta, Marcelo Cabús Klötzle, Antonio Carlos Figueiredo Pinto, Paulo Vitor Jordão da Gama Silva

tual de sua Receita Operacional Líquida (ROL) em P\&D. Todavia, após controlar o impacto do investimento em P\&D pelo Lucro e Patrimônio Líquido (PL), a variável não se mostrou significativa. Hungarato e Teixeira (2012) estudaram a relação entre gastos em $\mathrm{P} \& \mathrm{D}$ e o preço das ações no Brasil e também não encontraram uma relação positiva e significativa entre estas variáveis.

Pandit, Wasley e Zach (2011) avaliaram a relação entre inputs e outputs de inovação e o desempenho operacional futuro em empresas norte-americanas no período de 1972 a 2000. Utilizando o dispêndio com P\&D como proxy para os inputs de inovação e as citaçôes de patente para os outputs, os autores também encontraram uma relação positiva entre quantidade e qualidade das patentes com o desempenho operacional futuro.

Fernandes, Gonçalves e Perobelli (2013), além do investimento em P\&D, avaliaram a relação entre a geração de patentes e o valor de mercado das empresas no Brasil, entre 2007 e 2009. Dado o baixo volume de patentes registradas no Brasil, os autores não encontraram uma associação significativa com o número de patentes, mas surpreendentemente obtiveram uma relação negativa e significativa entre o investimento em intangíveis e o valor de mercado. Tal resultado pode ser atribuído ao período curto de tempo avaliado, o que leva os autores a concluírem que, no curto prazo, o mercado interpreta o investimento em P\&D como custo.

Hirshleifer, Hsu e Li (2013), por sua vez, utilizaram uma medida de eficiência propriamente dita, obtida pela divisão da quantidade de patentes ou citações de patentes pelo investimento em P\&D na bolsa norte-americana, de 1976 a 2006. Empregando diversos métodos usualmente aplicados para a identificação de retornos anormais associados à má precificação (mispricing), os autores verificaram fortes evidências de que a eficiência inovativa é subestimada no mercado norte-americano.

Ao analisarem o mercado norte-americano de 1980 a 2009, Cohen, Dietther e Malloy (2013) propõem uma nova medida de eficiência inovativa, chamada pelos autores de habilidade para inovar, que constitui na capacidade de converter os dispêndios com P\&D em vendas. Apesar de previsível e facilmente computável, o mercado parece ignorar o bom desempenho passado das firmas na alocação de seus orçamentos de P\&D. Dessa forma, estimando tal habilidade a partir do impacto do investimento passado em $P \& D$ na variação das vendas, os autores relatam que é possível obter um retorno anormal de $11 \%$ ao ano para uma estratégia long-short em um portfólio de empresas com elevado investimento em $\mathrm{P} \& \mathrm{D}$, comprado nas empresas com maior habilidade para inovar e vendido naquelas com menor habilidade. 
Silva et al. (2015) avaliaram o impacto dos dispêndios em P\&D em até três anos após o ano de sua ocorrência, para o período de 2005 a 2013, e também não encontraram evidências de associação entre o investimento em P\&D e retornos futuros no Brasil. Todavia, empresas engajadas em P\&D apresentaram uma relação positiva e significativa com o desempenho operacional futuro medido pela rentabilidade sobre o ativo.

Todavia, dentre as possíveis razões para a diversidade de conclusões obtidas quando se avalia a relação entre intensidade de P\&D e desempenho futuro está o fato de que a classificação de empresas por uma métrica de intensidade não distingue as firmas mais bem-sucedidas em auferir benefícios dos investimentos em P\&D. Dessa forma, em estudos mais recentes, alguns autores avaliam a relação entre medidas de eficiência inovativa e desempenho das empresas.

\section{Metodologia e base de dados}

A amostra utilizada neste estudo para avaliar a relação entre habilidade para inovar e retorno futuro é composta por todas as ações listadas na BM\&FBOVESPA, entre 01 de janeiro de 2001 e 31 de junho de 2014, excluídas as empresas financeiras e aquelas que não apresentavam os seguintes atributos: cotações mensais consecutivas para um período de 12 meses posterior ao de formação dos portfólios; valor de mercado em 31/dez. e 30/jun. anteriores ao período de formação do portfólio, com tolerância de cinco dias; e patrimônio líquido (PL) positivo em 31/dez. anterior ao período de formação do portfólio; por sua vez os dados foram aproveitados de 07/2009-07/2014.

Todas as informações financeiras e contábeis, com exceção daquelas sobre P\&D, foram extraídas da base de dados da Bloomberg. Os dados referentes a preços mensais deram origem à estimação dos retornos (RET) e momento (MOM), o valor de mercado (VM) foi utilizado para mensuração do tamanho, o patrimônio líquido (PL) sobre o VM originou o book-to-market (BTM) e as informações sobre vendas $(\mathrm{V})$ e margem bruta $(\mathrm{MB})$ foram empregadas na estimação da habilidade para inovar. Além disso, foram obtidos os dados de Capex, total de ativos, retorno sobre o ativo (ROA), margem operacional (MO) e margem Ebitda (lucro antes dos juros, impostos, depreciação e amortização). A utilização da variável margem deveu-se ao fato de se querer analisar também a influência do investimento em $\mathrm{P} \& \mathrm{D}$ na redução de custos e não somente no aumento de receita, como é comumente o caso nos EUA. 
As informaçōes sobre investimento em P\&D tiveram que ser extraídas diretamente das demonstrações financeiras anuais disponíveis no site da Comissão de Valores Mobiliários (CVM). A dificuldade de se obter esta informação por meio de bases de dados eletrônicas deve-se à migração recente do padrão contábil no Brasil para o IFRS, cujas alterações foram promovidas pela nova Lei das S/A (Lei $n^{\circ}$ 11.638/07 e 11.941/09). Assim, os registros de P\&D nestas bases apresentam-se em melhor qualidade somente a partir de 2010, quando a aplicação da nova na Lei das S/A passou a ser obrigatória.

Após as verificações das empresas listadas na BM\&FBOVESPA e das informações sobre investimento em P\&D, obteve-se um total de 48 empresas. A representatividade da amostra é significativa ao se compararem estudos anteriores em outros países e também quando se avalia o cenário brasileiro (empresas listadas na bolsa), principalmente em função do tamanho de ativos e valor de mercado das empresas consideradas no estudo.

Foram utilizados os retornos, assim como no paper base (COHEN; DIETTHER; MALLOY, 2013). O conceito de fluxo de caixa livre é mais amplo, sendo possível que uma empresa com fluxo de caixa positivo tenha retorno negativo, o que poderia enviesar os resultados e não foi objetivo do estudo. A ineficiência de mercado foi até certo ponto contornada, pois se ampliou o estudo com os fatores de Fama e French (1993) e Carhart (1997), o que deu mais robustez à análise. A amostra foi constituída por empresas que tinham retornos em pelo menos 12 meses consecutivos, o que eliminou aquelas com pouca liquidez.

Seguindo a metodologia proposta por Cohen, Dietther e Malloy (2013), estimou-se a habilidade para inovar em vendas por meio de regressões rolling do crescimento de vendas definido por $\log \left(\mathrm{V}_{\mathrm{t}} / \mathrm{V}_{\mathrm{t}-1}\right)$, contra o investimento passado em $\mathrm{P} \& \mathrm{D}$, medido por $\log \left(1+\mathrm{PD}_{\mathrm{t}-\mathrm{j}} / V_{\text {endas }} \mathrm{t}\right)$, onde $j$ representa a defasagem do investimento em $\mathrm{P} \& \mathrm{D}$, conforme as equaçōes 1 e 2 :

$$
\log \left(V_{i t} / V_{i t-1}\right)=\gamma_{0}+\gamma_{j} \log \left(1+P D_{i t-j} / V_{i t-j}\right)+\varepsilon_{i t}
$$

A mesma metodologia foi aplicada para estimar a habilidade em margem, apenas substituindo $\log \left(\mathrm{V}_{\mathrm{t}} / \mathrm{V}_{\mathrm{t}-1}\right)$ por $\log \left(1+\mathrm{MB}_{\mathrm{t}}\right)$

$$
\log \left(1+M B_{i t}\right)=\delta_{0}+\delta_{j} \log \left(1+P D_{i t-j} / V_{i t-j}\right)+\eta_{i t}
$$


Para rodar as regressōes foram utilizadas janelas de tempo de seis anos. Cohen, Dietther e Malloy (2013) analisaram janelas de tempo variando entre seis e dez anos e encontraram resultados bastante similares para os diferentes períodos escolhidos, tendo decidido pela utilização do ponto médio entre estes dois extremos. Neste trabalho optou-se pela utilização de uma janela de seis anos, dado o curto período de tempo disponível, minimizando assim a perda de observaçóes.

Para o mercado norte-americano, Cohen, Dietther e Malloy (2013) rodaram regressões individuais para cinco defasagens $\gamma_{j}\left(\delta_{j}\right) \quad(j=1$ a $j=5)$ e estimaram a habilidade para inovar de um determinado ano como a média desses cinco coeficientes. Todavia, em função do curto período de tempo para o qual foi possível obter dados em quantidade e qualidade razoável, somada a necessidade de seis anos de dados para estimar o coeficiente de habilidade, considerou-se somente o impacto das duas últimas defasagens ( $j=1$ e $j=2$ ). Dessa forma, para obter $\gamma_{1}$ de 2008, por exemplo, os dados de vendas de 2003 a 2008 foram regredidos contra os dados de P\&D de 2002 a 2007, e para estimação de $\gamma_{2}$ no mesmo ano, utilizaram-se as mesmas informações de vendas contra o investimento em P\&D de 2001 a 2006. A habilidade para inovar foi então obtida com a média entre $\gamma_{1}$ e $\gamma_{2}$. Esta dificuldade de acesso a informações de $\mathrm{P} \& \mathrm{D}$ em tempo suficiente também foi enfrentada por Nguyen, Nivoix e Noma (2010) no Japão, bem como em todas as referências citadas de pesquisas no Brasil. A opção pelo modelo de Fama-MacBeth deve-se à sua facilidade em lidar com painéis desbalanceados, dado que a quantidade de empresas é diferente em cada portfólio entre julho do ano $t$ e junho do ano $t+1$.

A Tabela 1 apresenta o sumário estatístico para portfólios formados em junho de cada ano $t$ com base na habilidade para inovar, comparando-os com as características dos portfólios formados a partir do nível de intensidade inovativa (investimentos em P\&D). A tabela mostra características e algumas medidas de desempenho dos portfólios de baixa habilidade para inovar, que contêm as empresas abaixo do $30^{\circ}$ percentil do coeficiente de habilidade $(\gamma$ ou $\delta$ ), e os portfólios de alta habilidade, representados pelas empresas com coeficiente de habilidade acima de $70^{\circ}$ percentil. Os portfólios P\&D_Hab alto são formados pela intersecção entre as empresas que alcançaram os 30\% maiores coeficientes de habilidade e aquelas localizadas entre os $30 \%$ maiores investimentos em $\mathrm{P} \& \mathrm{D}$, representando as empresas com alto investimento em $P \& D$ e alta habilidade para converter tal investimento em vendas ou margem. 
Raphael Braga da Silva, Luiz Felipe Jacques da Motta, Marcelo Cabús Klötzle, Antonio Carlos Figueiredo Pinto, Paulo Vitor Jordão da Gama Silva

TABELA 1

Sumário estatístico

\begin{tabular}{l|c|c|c|c|c|c}
\hline & \multicolumn{3}{|c|}{ Vendas } & \multicolumn{3}{c}{ Margem bruta } \\
\cline { 2 - 8 } Características e desempenho & $\begin{array}{c}\text { Hab. } \\
\text { baixa }\end{array}$ & $\begin{array}{c}\text { Hab. } \\
\text { alta }\end{array}$ & $\begin{array}{c}\text { P\&D_ } \\
\text { Hab. } \\
\text { alto }\end{array}$ & $\begin{array}{c}\text { Hab. } \\
\text { baixa }\end{array}$ & $\begin{array}{c}\text { Hab. } \\
\text { alta }\end{array}$ & $\begin{array}{c}\text { P\&D_ } \\
\text { Hab. } \\
\text { alto }\end{array}$ \\
\hline Painel A: Características & & & & & & \\
Tamanho (R MM) & 5.726 & 6.797 & 5.973 & 5.109 & 6.203 & 25.368 \\
Investimentos em P\&D (R\$ MM) & 32,54 & 24,85 & 31,38 & 30,22 & 32,83 & 297,73 \\
P\&D/vendas (\%) & 0,66 & 0,76 & 2,72 & 0,68 & 0,46 & 1,95 \\
P\&D/valor de mercado (\%) & 0,65 & 1,06 & 4,30 & 1,09 & 0,51 & 3,78 \\
Book to market equity (\%) & 0,90 & 0,79 & 0,64 & 0,88 & 0,78 & 0,77 \\
Capex/Ativos (\%) & 4,43 & 3,02 & 2,82 & 4,24 & 3,94 & 4,14 \\
Momento (-2-12) (\%) & 8,16 & $-3,11$ & 4,01 & $-10,15$ & 5,00 & 4,78 \\
Momento (-2-7) (\%) & 7,61 & 4,17 & 1,93 & 7,51 & 4,70 & $-2,50$ \\
Painel B: Desempenho & & & & & & \\
Retorno sobre o ativo (\%) & 3,87 & 4,50 & 5,44 & 3,41 & 5,08 & 5,25 \\
Margem operacional (\%) & 11,71 & 8,35 & 10,50 & 5,68 & 13,61 & 14,66 \\
Margem Ebitda (\%) & 19,35 & 17,07 & 19,28 & 13,02 & 21,05 & 19,31 \\
\hline
\end{tabular}

Fonte: Base de dados da Bloomberg e Comissão de Valores Mobiliários (CVM). Elaboração dos autores.

\section{Análise dos resultados}

\subsection{Retornos anormais para portfólios long-short}

Para avaliar se existe relação entre investimentos mais eficiente em recursos de $\mathrm{P} \& \mathrm{D}$ e retornos futuros, formaram-se portfólios baseados no coeficiente de habilidade computado conforme descrito na seção anterior. Os portfólios são formados com base nos $30^{\circ}$ e $70^{\circ}$ percentis de habilidade e rebalanceados anualmente. Como em Fama e French (1992), os portfólios anuais são formados entre julho do ano $t$ e junho do ano $t+1$.

Tendo em vista que a série histórica inicia-se em 2001, que as regressões rolling para estimação dos coeficientes de habilidade baseiam-se nas últimas seis observações e que a habilidade para inovar é obtida pela média de $\gamma_{j}$ (coeficiente de habilidade em vendas) ou $\delta_{j}$ (coeficiente de habilidade em margem) para $j=1$ e $j=2$, perdem-se sete observações anuais, sendo a primeira estimativa de habilidade obtida para o ano de 2008. 
Assim, considerando-se que os portfólios são formados com uma defasagem de três meses da publicação do investimento em $\mathrm{P} \& \mathrm{D}$, isto é, somente em março do ano seguinte, para garantir que todos os investidores tenham acesso à informação em tempo hábil para incorporá-las em seus processos de precificação, o primeiro portfólio inicia-se em julho de 2009, formado com base na habilidade para inovar de 2008.

Observando-se os mesmos critérios acima, também foram formados portfólios anuais (julho do ano $t$ até junho do ano $t+1$ ) baseados na intensidade de $\mathrm{P} \& \mathrm{D}$, medida pela razão $\mathrm{P} \& \mathrm{D} /$ vendas do ano anterior ao período de formação do portfólio, para o mesmo período amostral, entre julho de 2009 e junho de 2014. Além do retorno em excesso, para cada um dos portfólios são apresentados os retornos ajustados, usando cinco portfólios benchmark baseados no tamanho e 25 portfólios benchmark formados com base no tamanho e book-to-market, conforme Daniel et al. (1997).

Analisando a Tabela 2, podemos observar que não é possível extrair qualquer padrão de retornos a partir da ordenação simples por $\mathrm{P} \& \mathrm{D}$ ou habilidade. Assim como em Silva et al. (2015), o Painel A indica que, tanto para os portfólios igualmente podendaros (equally-weighted) quanto para os aqueles ponderados pelo valor de mercado (value-weighted) não há qualquer associação significativa entre intensidade de investimento em P\&D e retornos futuros, como pode ser visto na coluna spread, que representa o retorno de um portfólio comprado em ações de alta intensidade de investimento em P\&D e vendido em ações de baixa intensidade.

Os painéis $\mathrm{B}$ e $\mathrm{C}$ indicam que a construção de portfólios baseados exclusivamente na habilidade para inovar, seja em função da habilidade em converter os investimentos em P\&D em maiores vendas (painel B) ou em melhores margens por meio da redução de custos (painel C), não fornece indícios significativos da existência de relação entre habilidade para inovar e retornos futuros, indo contra o observado em Chan, Lakonishok e Sougiannis (2001). O portfólio equally-weighted formado a partir da habilidade em vendas foi o único a apresentar retorno positivo e significativo ao nível de 5\%. Todos os demais portfólios mostraram retornos não significativos, tendo os value-weighted, inclusive, apresentado spread negativo, conforme em Cohen, Dietther e Malloy (2013). 
Raphael Braga da Silva, Luiz Felipe Jacques da Motta, Marcelo Cabús Klötzle, Antonio Carlos Figueiredo Pinto, Paulo Vitor Jordão da Gama Silva

TABELA 2

Retornos mensais para portfólios baseados em intensidade de P\&D e habilidade - 2009-2014

\begin{tabular}{|c|c|c|c|c|c|c|c|c|}
\hline & \multicolumn{4}{|c|}{ Equally-weighted } & \multicolumn{4}{|c|}{ Value-weighted } \\
\hline Portfólios & Baixo & Médio & Alto & Spread & Baixo & Médio & Alto & Sprea \\
\hline \multicolumn{9}{|c|}{ Painel A: Portfólios P\&D } \\
\hline \multicolumn{9}{|c|}{ Retornos em excesso } \\
\hline Média & $-0,08$ & $-0,26$ & 0,46 & 0,54 & $-0,33$ & $-0,85$ & $-0,01$ & 0,32 \\
\hline t-estat & 0,84 & $-0,15$ & $-0,54$ & 0,88 & $-0,49$ & $-1,10$ & $-0,01$ & 0,52 \\
\hline \multicolumn{9}{|c|}{ Portfólio ajustado ao tamanho } \\
\hline Média & $-0,29$ & $-0,62$ & $-0,11$ & 0,18 & $-0,35$ & $-0,82$ & $-0,11$ & 0,23 \\
\hline t-estat & $-0,56$ & $-1,18$ & $-0,32$ & 0,35 & $-0,60$ & $-1,25$ & $-0,17$ & 0,38 \\
\hline
\end{tabular}

Portfólio ajustado ao tamanho e BTM

$\begin{array}{lllllllll}\text { Média } & -0,69 & 0,02 & -0,43 & 0,26 & -0,34 & -0,85 & -0,07 & 0,27 \\ \text { t-estat } & -0,94 & 0,03 & -1,02 & 0,38 & -0,53 & -1,15 & -0,10 & 0,44\end{array}$

Quantidade de ações

$\begin{array}{lllllll}\text { Média } & 14 & 18 & 14 & 14 & 18 & 14\end{array}$

\section{Painel B: Portfólios}

\section{habilidade em vendas}

Retornos em excesso

$\begin{array}{lllllllll}\text { Média } & -0,49 & 0,56 & 0,04 & 0,52 & -0,31 & -0,37 & -0,65 & -0,34 \\ \text { t-estat } & -0,88 & 1,26 & 0,06 & 1,07 & -0,36 & -0,56 & -0,94 & -0,51\end{array}$

Portfólio ajustado ao tamanho

$\begin{array}{lllllllll}\text { Média } & -0,58 & 0,35 & -0,02 & 0,56 & -0,26 & -0,48 & -0,62 & -0,36 \\ \text { t-estat } & -0,93 & 0,85 & -0,05 & 1,07 & -0,33 & -0,90 & -1,09 & -0,52\end{array}$

Portfólio ajustado ao tamanho e BTM

$\begin{array}{lllllllll}\text { Média } & -1,21 & 0,14 & 0,27 & 1,49 & -0,35 & -0,42 & -0,60 & -0,25 \\ \text { t-estat } & -1,87 & 0,32 & 0,43 & 2,24^{* *} & -0,41 & -0,70 & -0,91 & -0,36\end{array}$

Quantidade de ações

$\begin{array}{lllllll}\text { Média } & 10 & 13 & 10 & 10 & 13 & 10\end{array}$

\section{Painel C: Portfólios}

\section{habilidade em margem}

Retornos em excesso

$\begin{array}{lllllllll}\text { Média } & -0,48 & 0,69 & -0,08 & 0,40 & -0,41 & 0,33 & -1,13 & -0,72 \\ \text { t-estat } & -0,82 & 1,49 & -0,14 & 0,89 & -0,99 & 0,42 & -1,40 & -0,95\end{array}$

Portfólio ajustado ao tamanho

$\begin{array}{lllllllll}\text { Média } & -0,55 & 0,54 & -0,90 & -0,35 & -0,38 & 0,29 & -1,17 & -0,79 \\ \text { t-estat } & -1,05 & 1,25 & -1,58 & -0,69 & 0,98 & -1,04 & 0,43 & -1,68^{*}\end{array}$

Portfólio ajustado ao tamanho e BTM

$\begin{array}{lllllllll}\text { Média } & -0,18 & 0,35 & -0,94 & -0,76 & -0,41 & 0,41 & -1,11 & -0,71 \\ \text { t-estat } & -0,26 & 0,68 & -1,19 & -1,01 & -1,03 & 0,54 & -1,47 & -0,97\end{array}$

Quantidade de ações

$$
\text { Média }
$$

Fonte: Base de dados da Bloomberg e Comissão de Valores Mobiliários (CVM). Elaboração dos autores.

Nota: ${ }^{* * *},{ }^{* *} \mathrm{e}^{*}$ indicam significância ao nível de $1 \%, 5 \%$ e $10 \%$, respectivamente. BTM refere-se a book-to-market; foram usados preços de fechamento. 
Todavia, deve-se destacar que os portfólios baseados em habilidade incluem firmas que investem baixos percentuais de suas receitas em P\&D. Dessa forma, é possível que o sucesso passado relevante na determinação da real capacidade em converter investimento em $\mathrm{P} \& \mathrm{D}$ em resultado futuro esteja associado às empresas que realizem tais investimentos em maior magnitude, costumeiramente representadas pelas empresas líderes de setores, como visto em Lev; Radhakrishnan e Ciftci (2006). Para avaliar tal relação, é necessário construir uma estratégia de investimento baseada nas duas variáveis conjuntamente, quais sejam, intensidade de investimento em $P \& D$ e habilidade para inovar.

A Tabela 3 apresenta os retornos mensais médios dos portfólios formados a partir de uma dupla ordenação baseada em habilidade e P\&D/vendas, ambas considerando os $30^{\circ}$ e $70^{\circ}$ percentis. Dos nove portfólios formados a partir da intersecção entre habilidade para inovar e intensidade de $\mathrm{P} \& \mathrm{D}$, quatro encontram-se na Tabela 3: os portfólios com baixa habilidade para inovar e baixo P\&D; com baixa habilidade e alto P\&D; alta habilidade e baixo P\&D; e alta habilidade e alto P\&D. Os portfólios médios foram omitidos para otimizar a apresentação dos resultados.

A coluna spread apresenta os retornos mensais para um portfólio long-short em ações de alta habilidade com alta intensidade de P\&D e baixa habilidade com alta intensidade de P\&D. O objetivo é identificar se, entre empresas que investem elevados percentuais de suas receitas em $\mathrm{P} \& \mathrm{D}$, aquelas mais hábeis estão associadas a maiores retornos futuros.

De fato, como demonstra o painel A.1 da Tabela 3, para portfólios equally-weighted, o spread do retorno em excesso para portfólios baseados na habilidade em vendas é de $2,02 \%$ ao mês, significativo ao nível de $1 \%$, o que significa um retorno anual de $27,12 \%$ ao ano. Além disso, observa-se que, mesmo após controlar por outras características das firmas, a estratégia de investimento baseada em habilidade em vendas produz spreads significativos estatística e economicamente. Para portfólios controlados por tamanho, a estratégia produz retorno médio mensal de $1,96 \%$ e, quando ajustados por tamanho e book-to-market, o retorno anormal é de 1,69\%, o que representa retornos anuais de $26,23 \%$ e $22,28 \%$ ao ano, respectivamente.

Os portfólios equally-weighted baseados em habilidade em margem (painel B.1) também apresentam retorno em excesso positivo e significativo para o portfólio spread (alta habilidade/alto P\&D - baixa habilidade/alto $\mathrm{P} \& D)$. Ainda que em menor magnitude do que o retorno médio obtido pela estratégia baseada em habilidade em vendas, o spread de 1,41\% ao mês $(\mathrm{t}=2,27)$ é expressivo economicamente, equivalente a $18,30 \%$ ao ano. Todavia, 
Raphael Braga da Silva, Luiz Felipe Jacques da Motta, Marcelo Cabús Klötzle, Antonio Carlos Figueiredo Pinto, Paulo Vitor Jordão da Gama Silva

quando ajustados por outras características, os retornos médios produzidos pela estratégia baseada em habilidade em margem tornam-se não significativos, indicando que o retorno em excesso pode ser explicado pelo tamanho e book-to-market das firmas que compõem os portfólios long-short.

TABELA 3

Retornos mensais de portfólios com dupla ordenação - habilidade e intensidade de P\&D - 2009-2014

\begin{tabular}{|c|c|c|c|c|c|}
\hline \multirow{2}{*}{ Portfólios } & \multicolumn{2}{|c|}{ Habilidade baixa } & \multicolumn{2}{|c|}{ Habilidade alta } & \multirow[b]{2}{*}{ Spread } \\
\hline & P\&D baixo & P\&D alto & P\&D baixo & P\&D alto & \\
\hline
\end{tabular}

Painel A: Habilidade em vendas

Painel A.1: Equally-Weighted portfólios

Retornos em excesso

$\begin{array}{lrrrrc}\begin{array}{l}\text { Média } \\ \text { t-estat }\end{array} & -0,14 & -0,76 & -0,76 & 1,26 & 2,02 \\ \text { ustado ao tamanho } & -0,21 & -1,26 & -1,00 & 2,36^{* *} & 3,00^{* * *} \\ \begin{array}{l}\text { Média } \\ \begin{array}{l}\text { t-estat } \\ \text { t-sto ao tamanho e BTM }\end{array}\end{array} & -0,03 & -1,15 & -1,16 & 0,81 & 1,96 \\ \begin{array}{l}\text { Média } \\ \text { t-estat }\end{array} & -1,71 & -1,68 & 1,91^{*} & 2,83^{* * *} \\ & 0,03 & -1,37 & -1,61 & 0,32 & 1,69 \\ & 0,03 & -1,45 & -1,59 & 0,62 & 1,66^{*}\end{array}$

Painel A.2: Value-weighted portfólios

Retornos em excesso

$\begin{array}{lrrrrr}\begin{array}{l}\text { Média } \\ \text { t-estat }\end{array} & -0,11 & 0,59 & -1,33 & 0,60 & 0,00 \\ \text { ustado ao tamanho } & -0,15 & 0,89 & -1,40 & 1,11 & 0,00 \\ \begin{array}{l}\text { Média } \\ \text { t-estat }\end{array} & -0,17 & 0,59 & -1,43 & 0,56 & -0,04 \\ \begin{array}{l}\text { ustado ao tamanho e BTM } \\ \text { Média }\end{array} & -0,24 & 0,98 & -1,56 & 1,15 & -0,05 \\ \begin{array}{l}\text { Mestat } \\ \text { t-esta }\end{array} & -0,18 & 0,68 & -1,37 & 0,57 & -0,11 \\ & -0,25 & 1,06 & -1,45 & 1,07 & -0,14\end{array}$

Painel B: Habilidade em margem

Portfólio ajustado ao tamanho

Painel B.1: Equally-weighted portfólios

Retornos em excesso

$\begin{array}{lccccc}\begin{array}{l}\text { Média } \\ \text { t-estat }\end{array} & 0,23 & -1,02 & -0,62 & 0,39 & 1,41 \\ \begin{array}{l}\text { stado ao tamanho } \\ \begin{array}{l}\text { Média } \\ \text { t-estat }\end{array}\end{array} & 0,35 & -1,68^{*} & -1,14 & 0,71 & 2,27^{* *} \\ \begin{array}{l}\text { - } \\ \text { stado ao tamanho e BTM }\end{array} & 0,30 & -1,07 & -0,45 & -0,24 & 0,83 \\ \begin{array}{l}\text { Média } \\ \text { t-estat }\end{array} & 0,48 & -1,75^{*} & -0,72 & -0,58 & 1,15 \\ & 0,77 & -1,30 & -0,59 & -0,03 & 1,27 \\ \end{array}$

Painel B.2: Value-weighted portfólios

Retornos em excesso

\begin{tabular}{|c|c|c|c|c|c|}
\hline Média & $-0,68$ & $-0,48$ & $-0,96$ & 0,05 & 0,53 \\
\hline t-estat & $-0,84$ & $-0,70$ & $-1,49$ & 0,08 & 0,81 \\
\hline stado ao & & & & & \\
\hline Média & $-0,79$ & $-0,43$ & $-0,99$ & $-0,06$ & 0,37 \\
\hline t-estat & $-1,06$ & $-0,70$ & $-1,70^{*}$ & $-0,10$ & 0,55 \\
\hline stado ao & & & & & \\
\hline Média & $-0,68$ & $-0,53$ & $-0,96$ & 0,03 & 0,55 \\
\hline t-estat & $-0,85$ & $-0,79$ & $-1,53$ & 0,04 & 0,85 \\
\hline
\end{tabular}

Fonte: Base de dados da Bloomberg e Comissão de Valores Mobiliários (CVM). Elaboração dos autores.

Nota: ${ }^{* *},{ }^{* *} \mathrm{e}^{*}$ indicam significância ao nível de $1 \%, 5 \%$ e $10 \%$, respectivamente. BTM refere-se a book-to-market; foram usados preços de fechamento. 
Nenhum dos portfólios spread value-weighted, sejam os formados por habilidade em vendas ou em margem (painéis A.2 e B.2, respectivamente), apresentou qualquer padrão de associação com retornos futuros. A explicação para este resultado deve-se à elevada concentração do valor de mercado dos portfólios em uma única empresa. Para aqueles com alta habilidade e alto P\&D, a média anual de concentração do valor de mercado no maior portfólio é de aproximadamente $71 \%$, chegando a uma concentração de $90 \%$ naquele formado entre julho de 2013 e junho de 2014. Por esta razão, as próximas análises se concentrarão nos portfólios equally-weighted.

Os resultados obtidos nos painéis A.1 e B.1 indicam que firmas que possuem maior capacidade em converter seus investimentos em $\mathrm{P} \& \mathrm{D}$ em vendas (empresas de alta habilidade/alto P\&D) estão associadas a maiores retornos anormais futuros (elucidando EBERHART; MAXWELL; SIDDIQUE, 2004; HUNGARATO; SANCHES, 2006). Dado que para o mesmo período não foi possível identificar retornos anormais para estratégias long-short baseadas exclusivamente em P\&D ou habilidade, tais resultados sugerem que, de fato, o coeficiente de habilidade é capaz de distinguir empresas que investem montantes equivalente em $\mathrm{P} \& \mathrm{D}$. Isto é, para duas empresas de igual intensidade em $P \& D$, o coeficiente de habilidade é capaz de distinguir aquela com maior probabilidade de obter êxito em seus investimentos.

O mesmo não foi observado quando se utilizou o coeficiente de habilidade em margem, o que sugere que inovaçóes associadas ao aumento das vendas, como o lançamento de produtos novos ou o aperfeiçoamento de produtos já existentes, produzem maiores retornos anormais futuros do que as inovações relacionadas com a melhoria de eficiência na produção e redução de custos.

\subsection{Retornos ajustados aos fatores de Fama e French (1993) e Carhart (1997)}

Além da formação de portfólios long-short, avaliou-se a existência de retornos anormais associados ao investimento em firmas com maiores coeficientes de habilidade para inovar e o mesmo nível de intensidade de P\&D, por meio dos modelos de três fatores de Fama e French (1993) e Carhart (1997), conforme as equações 3 e 4, respectivamente.

$$
R_{i t}-r f_{i}=\alpha_{i t}+\beta_{i t} M K T_{t}+s_{i t} S M B_{t}+h_{i t} H M L_{t}+\varepsilon_{i t}
$$


Raphael Braga da Silva, Luiz Felipe Jacques da Motta, Marcelo Cabús Klötzle, Antonio Carlos Figueiredo Pinto, Paulo Vitor Jordão da Gama Silva

$$
R_{i t}-r f_{i}=\alpha_{i t}+\beta_{i t} M K T_{t}+s_{i t} S M B_{t}+h_{i t} H M L_{t}+u_{i t} U M D_{t}+\varepsilon_{i t}
$$

Onde $R_{i, t}-r f_{t}$ representa o retorno mensal de cada ação em excesso à taxa livre de risco, medida pelo CDI; $M K T$ é o prêmio do portfólio de mercado, obtido por meio da diferença entre os retornos mensais do portfólio de mercado e da taxa livre de risco. Como proxy do portfólio de mercado utilizou-se o retorno médio do Ibovespa.

Os fatores $S M B$ e $H M L$ representam, respectivamente, o retorno das ações menores menos o retorno das ações maiores e a diferença entre o retorno das ações com alto índice book-to-market e das ações com baixo índice book-to-market. Para estimar estes fatores adotou-se a metodologia proposta por Fama e French (1993). O fator UMD representa o fator momento e é obtido pela diferença dos retornos médios mensais das firmas com os $30 \%$ maiores retornos nos 11 meses que antecedem o período de formação dos portfólios, com defasagem de um mês, e os retornos médios mensais dos portfólios com os 30\% menores retornos prévios (-2-12), conforme Carhart (1997).

Em função das razôes expostas na seção anterior, somente os coeficientes para os portfólios equally-weighted são apresentados na Tabela 4. Além dos coeficientes para os portfólios com baixa habilidade para inovar-baixo P\&D, baixa habilidade-alto P\&D, alta habilidade-baixo P\&D e alta habilidade-alto P\&D, a coluna spread apresenta os coeficientes para um portfólio hedge comprado em ações de alta habilidade-alto $P \& D$ e vendido em baixa habilidade-alto P\&D. A estatística $t$ foi calculada com base no erro padrão utilizando a metodologia de Newey e Kenneth (1987) para correção da heterocedasticidade e autocorrelação serial.

De acordo com os painéis A e B da Tabela 4, observa-se que, para uma estratégia de investimento baseada na habilidade em vendas, o portfólio hedge, assim como o aquele de alta habilidade-alto $\mathrm{P} \& \mathrm{D}$, possui retornos anormais positivos e altamente significativos estatisticamente. Cabe destacar que os retornos anormais obtidos nos modelos de três e quatro fatores coadunam com aqueles obtidos na seção anterior, a partir da formação de portfólios long-short. O alfa obtido no modelo Fama e French (1993) é de 2,19\% ao mês ( $\mathrm{t}=3,14)$ e no modelo Carhart (1997) é de $2,11 \%(\mathrm{t}=2,74)$, equivalentes a $29,69 \%$ e $28,48 \%$ a.a., respectivamente, em linha com os $27,12 \%$ a.a. encontrados no painel A.1 da Tabela 3.

Tais resultados reforçam a hipótese de que a habilidade para inovar, considerando o mesmo nível de investimento em P\&D, está associada a maiores retornos futuros e, ainda que tal informação seja observável e facilmente estimada, os investidores não as refletem em seus processos de precificação, permitindo a obtenção de retornos anormais significativos estatística e economicamente a partir de uma estratégia de investimento baseada em empresas intensivas em P\&D 
TABELA 4

Retornos ajustados ao risco para portfólios com dupla ordenação em habilidade e P\&D - 2009-2014

\begin{tabular}{|c|c|c|c|c|c|}
\hline \multirow[b]{2}{*}{ Portfólios } & \multicolumn{2}{|c|}{ Habilidade baixa } & \multicolumn{2}{|c|}{ Habilidade alta } & \multirow[b]{2}{*}{ Spread } \\
\hline & $\begin{array}{l}\text { P\&D } \\
\text { baixo }\end{array}$ & $\begin{array}{c}\text { P\&D } \\
\text { alto }\end{array}$ & $\begin{array}{l}\text { P\&D } \\
\text { baixo }\end{array}$ & $\begin{array}{c}\text { P\&D } \\
\text { alto }\end{array}$ & \\
\hline \multicolumn{6}{|c|}{ Painel A: Coeficientes Fama e French (1993) para habilidade em vendas } \\
\hline$\alpha$ & 0,62 & $-0,50$ & 0,09 & 1,69 & 2,19 \\
\hline t-estat & 0,98 & $-0,92$ & 0,11 & $3,72^{* * *}$ & $3,14^{* * *}$ \\
\hline MKT & 0,37 & 0,43 & 0,72 & 0,61 & 0,18 \\
\hline t-estat & $2,90^{* * *}$ & $3,20^{* * *}$ & $7,74^{* * *}$ & $6,55^{* * *}$ & $1,58^{* * *}$ \\
\hline SMB & $-0,35$ & 0,24 & $-0,29$ & 0,31 & 0,07 \\
\hline t-estat & $-1,70^{*}$ & 1,39 & $-1,39$ & 1,31 & 0,23 \\
\hline HML & 0,52 & 0,09 & 0,33 & 0,19 & 0,10 \\
\hline t-estat & $2,24^{* *}$ & 0,46 & 1,11 & 0,86 & 0,33 \\
\hline \multicolumn{6}{|c|}{ Painel B: Coeficientes Carhart (1997) para habilidade em vendas } \\
\hline$\alpha$ & 0,37 & $-0,67$ & 0,08 & 1,44 & 2,11 \\
\hline t-estat & 0,50 & $-1,07$ & 0,09 & $2,61^{* * *}$ & $2,74^{* * *}$ \\
\hline MKT & 0,40 & 0,45 & 0,72 & 0,64 & 0,19 \\
\hline t-estat & $3,05^{* * *}$ & $3,28^{* * *}$ & $7,41^{* * *}$ & $7,59^{* * *}$ & 1,62 \\
\hline SMB & $-0,27$ & 0,29 & $-0,29$ & 0,39 & 0,09 \\
\hline t-estat & $-1,11$ & 1,61 & $-1,27$ & 1,49 & 0,30 \\
\hline HML & 0,61 & 0,15 & 0,33 & 0,28 & 0,13 \\
\hline t-estat & 2,40 & 0,75 & 1,00 & 1,20 & 0,40 \\
\hline UMD & 0,31 & 0,21 & 0,02 & 0,30 & 0,09 \\
\hline t-estat & 1,15 & 0,77 & 0,07 & 1,49 & 0,37 \\
\hline \multicolumn{6}{|c|}{ Painel C: Coeficientes Fama e French (1993) para habilidade em margem } \\
\hline$\alpha$ & 1,04 & $-0,53$ & $-0,08$ & 0,89 & 1,42 \\
\hline t-estat & $1,88^{*}$ & $-0,91$ & $-0,12$ & $2,11^{* *}$ & $2,48^{* *}$ \\
\hline MKT & 0,71 & 0,43 & 0,29 & 0,69 & 0,26 \\
\hline t-estat & $6,48^{* * *}$ & $3,16^{* * *}$ & $2,88^{* * *}$ & $7,98^{* * *}$ & 1,56 \\
\hline SMB & $-0,44$ & 0,42 & $-0,46$ & 0,36 & $-0,06$ \\
\hline t-estat & $-2,66^{* * *}$ & 1,35 & $-2,59^{* * *}$ & $1,93^{*}$ & $-0,22$ \\
\hline HML & 0,19 & 0,51 & 0,21 & 0,24 & $-0,28$ \\
\hline t-estat & 0,97 & $1,94^{*}$ & 1,41 & 1,25 & $-0,83$ \\
\hline \multicolumn{6}{|c|}{ Painel D: Coeficientes Carhart (1997) para habilidade em margem } \\
\hline$\alpha$ & 0,64 & $-0,50$ & $-0,18$ & 0,67 & 1,17 \\
\hline t-estat & 1,06 & $-0,94$ & $-0,26$ & 1,35 & $1,93^{*}$ \\
\hline MKT & 0,76 & 0,43 & 0,30 & 0,72 & 0,29 \\
\hline t-estat & $7,10^{* * *}$ & $2,85^{* * *}$ & $2,86^{* * *}$ & $8,00^{* * *}$ & 1,62 \\
\hline SMB & $-0,32$ & 0,41 & $-0,43$ & 0,43 & 0,01 \\
\hline t-estat & $-1,74^{*}$ & 1,25 & $-2,06^{* *}$ & $2,14^{* *}$ & 0,05 \\
\hline HML & 0,34 & 0,50 & 0,25 & 0,32 & $-0,19$ \\
\hline t-estat & 1,39 & $1,95^{*}$ & 1,51 & 1,56 & $-0,57$ \\
\hline UMD & 0,49 & $-0,04$ & 0,13 & 0,27 & 0,31 \\
\hline t-estat & $2,36^{* *}$ & $-0,14$ & 0,70 & 1,40 & 1,17 \\
\hline
\end{tabular}

Fonte: Base de dados da Bloomberg e Comissão de Valores Mobiliários (CVM). Elaboração dos autores. Nota: ${ }^{* * *},{ }^{* *} \mathrm{e}{ }^{*}$ indicam significância ao nível de $1 \%, 5 \%$ e $10 \%$, respectivamente. 
Cabe destacar ainda que os portfólios hedge não possuem coeficientes significativos para nenhum dos demais fatores de risco, indicando que os retornos desse portfólio não estão expostos a nenhum desses fatores.

Os resultados do painel $\mathrm{C}$ indicam que, para portfólios baseados na habilidade em margem-alto $P \& D$, assim como para a estratégia baseada em habilidade em vendas-alto $\mathrm{P} \& \mathrm{D}$, o modelo de três fatores apresenta retornos anormais positivos e significativos para os portfólios de alta habilidade-alto P\&D e para o portfólio hedge, todavia, em menor magnitude e significância estatística. Para o portfólio hedge o retorno anormal foi de $1,42 \%$ ao mês $(\mathrm{t}=2,48)$ ou $18,44 \%$ ao ano, também em linha com os $18,30 \%$ ao ano obtidos por meio da formação de portfólios no painel B.1 da Tabela 3.

Quando considerados os quatro fatores (painel D), somente o portfólio hedge possui retorno anormal significativo para habilidade em margem-alto $\mathrm{P} \& \mathrm{D}$, reduzindo sua magnitude em relação ao modelo de três fatores para $1,17 \%$ ao mês $(\mathrm{t}=1,93)$.

Os resultados da Tabela 4 indicam que uma estratégia de investimento baseada tanto na habilidade em vendas-alto P\&D quanto na habilidade em margem-alto $\mathrm{P} \& \mathrm{D}$ fornecem retornos positivos não explicados pelos demais fatores de risco. Todavia, assim como na seção anterior, os maiores retornos anormais positivos obtidos a partir da formação de um portfólio hedge em habilidade em vendas-alto $\mathrm{P} \& \mathrm{D}$ indicam que inovaçôes em produtos e serviços, isto é, aquelas mais relacionadas à probabilidade de produzirem incremento nas vendas, estão associadas a maiores retornos futuros do que as inovações que proporcionam redução de custos e, por sua vez, melhoria nas margens.

\subsection{Regressões cross-sectional de Fama e Macbeth}

Para suportar os indícios da relação encontrada entre a habilidade para inovar e retornos futuros nas seções anteriores, principalmente em vendas, nesta seção utilizou-se um conjunto de regressões cross-sectional mensais de Fama-MacBeth (1973), em que a variável de interesse é a interação entre alta habilidade e alto $\mathrm{P} \& D$.

Como apontado anteriormente, a opção pelo modelo de Fama-MacBeth deve-se à facilidade do modelo em lidar com painéis desbalanceados. Além disso, outra vantagem importante do método, segundo Goyal (2012), é que ele dispensa o cálculo das variâncias dos coeficientes em cada período e, por conseguinte, das 
correlações transversais, mas, por outro lado, no segundo estágio, computa a variância dos coeficientes médios calculados usando a série temporal desses coeficientes.

A Tabela 5 apresenta os quatro modelos testados para habilidade em vendas. Os coeficientes de habilidade foram calculados conforme descrito anteriormente na seção sobre metodologia, sendo que a interação entre alta habilidade e alto P\&D considera os mesmos percentis informados nesta seção.

A equação 1 (Eq.1) apresenta os resultados das regressões somente para as variáveis controle, cujos efeitos sobre os retornos futuros são amplamente relatados na literatura. O tamanho é dado pelo log do valor de mercado no mês $t-1$, o book-to-market é medido pelo log do book-to-market em dezembro do ano $t$ - 1 e o momento representa o retorno acumulado em 11 meses anteriores ao mês $t$ com um mês de defasagem (do mês $t-12$ ao mês $t$-2). Para o período analisado, entre julho de 2009 e junho de 2014, somente o fator momento se mostrou significativo na explicação da variação dos retornos futuros.

TABELA 5

Retornos ajustados ao risco para portfólios com dupla ordenação em habilidade e P\&D - 2009-2014

\begin{tabular}{|c|c|c|c|c|}
\hline Portfólios & Eq. 1 & Eq. 2 & Eq. 3 & Eq. 4 \\
\hline P\&D alto*Hab. alta & & 0,558 & 0,347 & 0,403 \\
\hline t-estat & & 0,918 & 0,435 & 0,514 \\
\hline P\&D alto*Hab. baixa & & & & $-0,517$ \\
\hline t-estat & & & & $-0,454$ \\
\hline Hab. alta & & & $-0,033$ & $-0,369$ \\
\hline t-estat & & & $-0,087$ & $-0,826$ \\
\hline Hab. baixa & & & & $-0,732$ \\
\hline t-estat & & & & $-1,426$ \\
\hline P\&D alto & & & 0,347 & 0,339 \\
\hline t-estat & & & 0,590 & 0,615 \\
\hline P\&D baixo & & & & $-0,032$ \\
\hline t-estat & & & & $-0,079$ \\
\hline Tamanho & $-0,138$ & $-0,135$ & $-0,047$ & 0,021 \\
\hline t-estat & $-0,427$ & $-0,420$ & $-0,134$ & 0,058 \\
\hline Book-to-market & $-0,454$ & $-0,514$ & $-0,517$ & $-0,425$ \\
\hline t-estat & $-0,873$ & $-0,982$ & $-0,913$ & $-0,730$ \\
\hline \multirow[t]{2}{*}{ Momento(-2,-12) } & 0,020 & 0,019 & 0,019 & 0,018 \\
\hline & $2,290^{* *}$ & $2,177^{* *}$ & $2,132^{* *}$ & $2,067^{* *}$ \\
\hline Número de meses & 60 & 60 & 60 & 60 \\
\hline $\begin{array}{l}\text { Número de obser- } \\
\text { vacōes }\end{array}$ & 2.880 & 2.880 & 2.880 & 2.880 \\
\hline
\end{tabular}

Fonte: Base de dados da Bloomberg e Comissão de Valores Mobiliários (CVM). Elaboração dos autores.

Nota: ${ }^{* *},{ }^{* *} \mathrm{e}^{*}$ indicam significância ao nível de $1 \%, 5 \%$ e $10 \%$, respectivamente. 
A equação 2 (Eq.2) inclui a variável de interesse, dada pela interação entre alto P\&D e alta habilidade, que tais variáveis - habilidade e P\&D - são representadas por uma dummy igual a 1 para firmas acima do percentil $70^{\circ}$ e 0 nos demais casos. Ainda que tenha apresentado sinal positivo como esperado, a interação entre alto $\mathrm{P} \& \mathrm{D}$ e alta habilidade não se mostrou significativa na explicação dos retornos.

A equação 3 (Eq.3) inclui as variáveis habilidade e P\&D altos individualmente e a equação 4 (Eq.4) adiciona à equação 3 as variáveis habilidade baixa, P\&D baixo e a interação entre elas, também mensuradas por uma dummy, neste caso igual a 1 para firmas abaixo do $30^{\circ}$ percentil e 0 nos demais casos. Ambas as equações continuam sugerindo que, para o período avaliado, somente o momento é significativo na explicação dos retornos.

Além das equações acima, em resultados não reportados foram testados mais três modelos substituindo a variável $\mathrm{P} \& \mathrm{D}$ dummy nas equaçóes 2 a 4 , por uma variável contínua medida pelo $\log (1+\mathrm{P} \& \mathrm{D} /$ Vendas $)$ em dezembro do ano anterior ao período de formação do portfólio. Além disso, testamos todas as equações mencionadas acima substituindo a habilidade em vendas pela habilidade em margem. Em todos eles a variável de interesse apresentou resultado positivo, mas não significativo e a única variável significativa estatisticamente foi o momento.

A Tabela 6 apresenta a matriz de correlação entre as variáveis $P \& D$, habilidade em margem (Hab_MB), habilidade em vendas (Hab_Vendas) e outras variáveis utilizadas no estudo. $\mathrm{O}$ objetivo principal da análise reside na verificação da correlação entre o investimento em $\mathrm{P} \& \mathrm{D}$ e os coeficientes de habilidade estimados. Os resultados indicam que a correlação entre o investimento em $P \& D$ e habilidade não é significativa.

Todavia, a correlação entre a habilidade em vendas e a habilidade em margem mostrou-se negativa e significativa ao nível de 5\%, sugerindo que, ou as empresas possuem ênfase em uma estratégia de inovação associada ao incremento das vendas, ou sua estratégia está mais fortemente associada à redução de custos.

O investimento em P\&D também se mostrou fortemente associado a empresas maiores, o que pode ser observado pelas altas correlações da variável com o valor de mercado e com o patrimônio líquido. A correlação entre as variáveis valor de mercado e patrimônio líquido também se mostrou elevada, devido ao fato de ambas serem uma referência ao tamanho da empresa. Observa-se, porém, que quando se considerou o investimento em P\&D ajustado pelas vendas, a correlação com o tamanho não se mostrou significativa. 
TABELA 6

Matriz de correlação das variáveis do estudo

\begin{tabular}{lccccccc}
\hline Variáveis & P\&D & HAB_MB & $\begin{array}{c}\text { HAB_ } \\
\text { Vendas }\end{array}$ & BTM & Tamanho & $\begin{array}{c}\text { P\&D/ } \\
\text { Vendas }\end{array}$ & PL \\
\hline P\&D & 1,0000 & & & & & \\
t-estat & - & & & & & \\
HAB_MB & $-0,0437$ & 1,0000 & & & & & \\
t-estat & $-0,1817$ & - & & & & & \\
& & & & & & & \\
HAB_Vendas & $-0,0238$ & $-0,2922^{* *}$ & 1,0000 & & & \\
t-estat & $-0,1328$ & $-1,9307$ & - & & & & \\
& & & & & & & \\
BTM & $-0,0343$ & $-0,0465$ & 0,0638 & 1,0000 & & \\
t-estat & $-0,1466$ & $-0,3547$ & 0,3042 & - & & \\
& & & & & & & \\
Valor de Mercado & $0,9410^{* * *}$ & $-0,0426$ & $-0,0446$ & $-0,0644$ & 1,0000 & & \\
t-estat & 15,5477 & $-0,1812$ & $-0,2280$ & $-0,3146$ & - & \\
& & & & & & & \\
P\&D/Vendas & 0,0750 & $-0,0596$ & 0,0163 & $-0,1417$ & $-0,0323$ & 1,0000 & \\
t-estat & 0,4177 & $-0,2661$ & 0,0848 & $-0,7788$ & $-0,1561$ & - \\
& & & & & & \\
PL & 0,8733 & $-0,0706$ & $-0,0465$ & 0,0848 & $0,9598^{* * *}$ & $-0,0579$ & 1,0000 \\
t-estat & $10,3656^{* * *}$ & $-0,3500$ & $-0,2515$ & 0,5210 & 23,9870 & $-0,3000$ & - \\
\hline
\end{tabular}

Fonte: Base de dados da Bloomberg e Comissão de Valores Mobiliários (CVM). Elaboração dos autores.

Nota: ${ }^{* *},{ }^{* *} \mathrm{e}^{*}$ indicam significância ao nível de $1 \%, 5 \%$ e $10 \%$, respectivamente. BTM refere-se a book-to-market e PL ao patrimônio líquido.

\section{Conclusões}

Baseados na proposta de mensuração da habilidade para inovar de Cohen, Dietther e Malloy (2013), este estudo estimou a habilidade para inovar das empresas no mercado de capitais brasileiro com base em sua capacidade de converter seus dispêndios em $\mathrm{P} \& \mathrm{D}$ em vendas (habilidade em vendas) e redução de custos de produção (habilidade em margem).

A interação do coeficiente de habilidade para inovar com o nível de intensidade em P\&D permitiu a formação de uma estratégia de investimento comprada em empresas com alta intensidade e alta habilidade para inovar e vendida naquelas que investem montante equivalente em P\&D, mas que possuem baixa habilidade. Dado 
Raphael Braga da Silva, Luiz Felipe Jacques da Motta, Marcelo Cabús Klötzle, Antonio Carlos Figueiredo Pinto, Paulo Vitor Jordão da Gama Silva

que ambos os portfólios - de alta e baixa habilidade - estão acima do $70^{\circ}$ percentil de dispêndio em P\&D, a existência de retornos anormais positivos associados a esta estratégia reflete uma subprecificação da expertise das empresas em converter seus dispêndios em benefícios futuros.

De fato, quando considerada a habilidade em vendas, uma estratégia long-short produz um spread de retorno em excesso de $27,12 \%$ ao ano, significativo ao nível de $1 \%$, para o período analisado. Mesmo após controlar por tamanho e book-to-market, a estratégia continua apresentando retornos anormais positivos e significativos, de $22,28 \%$ ao ano $(t=1,66)$.

A mesma estratégia, quando baseada na habilidade em margem, continua apresentando retorno em excesso significativo de $18,30 \%$ ao ano $(\mathrm{t}=2,27)$, mas em menor magnitude e com menor significância estatística quando comparada com uma estratégia que distingue as empresas com base na sua capacidade de converter dispêndio em P\&D em vendas. Adicionalmente, quando controlados os efeitos do tamanho e book-to-market, a estratégia baseada em habilidade em margem não apresentou retornos significativos.

Quando da formação de portfólios baseados exclusivamente na intensidade de P\&D e na habilidade para inovar, separadamente, não foram encontradas evidências de associação entre estas características individualmente e retornos futuros, sugerindo que, de fato, a interação entre alta habilidade e alto P\&D é capaz de distinguir a habilidade da firma na consecução dos objetivos de seus planos de inovação.

Os retornos anormais obtidos por meio das regressões de Fama e French (1993) e Carhart (1997) coadunam com os resultados obtidos por meio da formação de portfólios. No modelo de três fatores, o alfa do portfólio hedge, comprado em alta habilidade em vendas com alto $P \& D$ e vendido em baixa habilidade em vendas com alto P\&D, foi de 29,69\% ao ano. No modelo de quatro fatores o alfa foi de $28,48 \%$. Ambos significativos ao nível de $1 \%$ e em linha com o resultado obtido por meio da formação de portfólios, de 27,12\%. Para habilidade em margem, os resultados das regressōes também se alinham aos da formação de portfólios, sendo novamente menores em magnitude e significância estatística.

Tais resultados, além de indicarem que de fato o mercado de capitais parece ignorar a habilidade de as firmas alocarem seus orçamentos de P\&D com eficiência, sugerem que as inovações associadas ao incremento das vendas produzem retornos futuros maiores do que aquelas associadas à redução de custos.

Adicionalmente, rodaram-se regressões mensais conforme Fama-MacBeth (1973) para avaliar a relação da interação entre alta habilidade-alto $\mathrm{P} \& \mathrm{D}$ e retornos futuros, 
controlando por outras características amplamente relatadas na literatura e, neste caso, para o período analisado, apenas o fator momento mostrou-se significativo na explicação dos retornos. Ainda que o coeficiente da variável de interesse tenha apresentado sinal positivo, como esperado, e a interação entre baixa habilidade e alto $\mathrm{P} \& \mathrm{D}$ tenha apresentado relação negativa com os retornos, ambos não apresentaram significância estatística.

Por fim, sugere-se que, para novas pesquisas, se avalie a capacidade das firmas de converterem seus esforços de $\mathrm{P} \& \mathrm{D}$ não somente em vendas ou margem, mas também em outros resultados tangíveis, como número de patentes, citações de patentes, novos produtos, receitas oriundas de novos produtos, etc. Além disso, deve-se avaliar também a possibilidade de se considerarem os esforços de inovação de maneira mais ampla, não se limitando aos dispêndios em $P \& D$. A realização de testes por meio da interação entre a intensidade de investimento em $P \& D$ e investimento em outras rubricas, como investimento em Capex ou marketing, também podem complementar as conclusões obtidas neste estudo. Trabalhos futuros poderiam ainda identificar informações disponíveis capazes de servir como proxy para atividades inovativas adicionais ao P\&D, o que não foi foco da presente análise.

\section{Referências bibliográficas}

ALVES, A.; SILVA, T.; MACEDO, M.; MARQUES, J. A relevância dos gastos com P\&D para o mercado brasileiro de capitais: um estudo com distribuidoras de energia elétrica no período de 2002-2009. Revista de Administração e Inovação, v. 8, n. 2, p. 216-239, 2010.

CARHART, M. M. On persistence in mutual fund performance. Journal of Finance, v. 52, n. 1, p. 57-82, 1997.

CHAN, L. K. C; LAKONISHOK, J.; SOUGIANNIS, T. The stock market valuation of research and development expenditures. Journal of Finance, v. 56, n. 6, p. 2431-56, 2001.

COHEN, L.; DIETHER, K.; MALLOY, C. Misvaluing innovation. The Review of Financial Studies, v. 26, n. 3, p. 635-666, 2013.

DANIEL, K.; GRINBLATT, M.; TITMAN, S.; WERMERS, R. Measuring mutual fund performance with characteristic-based benchmarks. Journal of Finance, v. 52, n. 3, p. 103558, 1997.

EBERHART, A. C.; MAXWELL, W. F.; SIDDIQUE, A. R. An examination of long-term excess stock returns and operating performance following R\&D increases. Journal of Finance, v. 59, n. 2, p. 623-651, 2004. 
Raphael Braga da Silva, Luiz Felipe Jacques da Motta, Marcelo Cabús Klötzle, Antonio Carlos Figueiredo Pinto, Paulo Vitor Jordão da Gama Silva

FAMA, E.; FRENCH, K. Common risk factors in the returns on stocks and bonds. Journal of Financial Economics, v. 33, n. 1, p. 3-56, 1993.

FAMA, E.; MACBETH, J. Risk, return, and equilibrium: empirical tests. Journal of Political Economy, v. 81, n. 3, p. 607-636, 1973.

FERNANDES, G.; GONÇALVES, E.; PEROBELLI, F. Capital intangível e patentes: uma análise para as empresas brasileiras. In: XIII ENCONTRO BRASILEIRO DE FINANÇAS. Anais... Rio de Janeiro: PUC-RJ, 2013.

GOYAL, A. Empirical cross-sectional asset pricing: a survey. Financial Markets and Portfolio Management, v. 26, n. 1, p. 3-38, 2012.

GU, F. Innovation, future earnings, and market efficiency. Journal of Accounting, Auditing and Finance, v. 20, n. 4, p. 385-418, 2005.

HIRSHLEIFER, D. A.; HSU, P. H.; LI, D. Innovative efficiency and stock returns. Journal of Financial Economics, v. 107, n. 3, p. 632-654, 2013.

HUNGARATO, A.; SANCHES, M. A relevância dos gastos em P\&D para o preço das ações de empresas listadas na bovespa. In: SIMPÓSIO FUCAPE DE PRODUÇÃO CIENTÍFICA, 4. Anais... Vitória: Fucape, 2006. CD-ROM.

HUNGARATO, A.; TEIXEIRA, A. A Pesquisa e Desenvolvimento e os preços das ações das empresas brasileiras: um estudo empírico na Bovespa. Revista de Educação e Pesquisa em Contabilidade, v. 6, n. 3, p. 282-298, 2012.

LEV, B.; SOUGIANNIS, T. The capitalization, amortization, and value-relevance of R\&D. Journal of Accounting and Economics, v. 21, n. 1, p. 107-138, 1996.

LEV, B.; SARATH, B.; SOUGIANNIS, T. R\&D reporting biases and their consequences. Contemporary Accounting Research, v. 22, n. 4, p. 977-1026, 2005.

LEV, B.; RADHAKRISHNAN, S.; CIFTCI, M. The stock market valuation of $R \& D$ leaders. New York: New York University, 2006 (NYU Working Paper, n.2451/27475). Disponível em: <http://ssrn.com/abstract=1280696>.

NEWEY, W.; KENNETH, W. A simple, positive semi-definite, heteroscedastic and autocorrelation consistent covariance matrix. Econometrica, v. 55, n. 3, p. 703-708, 1987.

NGUYEN, P.; NIVOIX S.; NOMA, M. The valuation of R\&D expenditures in Japan. Journal of Accounting and Economics, v. 50, n. 4, p. 899-920, 2010.

PANDIT, S.; WASLEY, C. E.; ZACH, T. The effect of R\&D inputs and outputs on the relation between the uncertainty of future operating performance and $R \& D$ expenditures. Journal of Accounting, Auditing, and Finance, v. 26, n. 1, p.121-144, 2011. 
Inovação e a capacidade de apropriar benefícios associados aos investimentos em P\&D no Brasil

PENMAN, S. H.; ZHANG, X. J. Accounting conservatism, the quality of earnings, and stock returns. Accounting Review, v. 77, n. 2, p. 237-264, 2002.

SILVA, R.; KLOTZLE, M.; FIGUEIREDO, A. C.; MOTTA, L. F. Innovative intensity and its impact on the performance of firms in Brazil. Research in International Business and Finance, v. 34, n. 1, p. 1-16, 2015.

SOUGIANNIS, T. The accounting valuation of corporate R\&D. The Accounting Review, v. 69 , n. 1, p. 44-68, 1994. 
